\title{
Nucleus pulposus phenotypic markers to determine stem cell differentiation: fact or fiction?
}

\author{
Abbey A. Thorpe ${ }^{1}$, Abbie L.A. Binch ${ }^{1}$, Laura B. Creemers ${ }^{2}$, Christopher Sammon ${ }^{3}$ \\ and Christine L. Le Maitre ${ }^{1}$ \\ ${ }^{1}$ Biomolecular Sciences Research Centre, Sheffield Hallam University, Sheffield, UK \\ 2 UMC Utrecht, Orthopaedics Department, Utrecht, Netherlands \\ ${ }^{3}$ Materials and Engineering Research Institute, Sheffield Hallam University, Sheffield, UK \\ Correspondence to: Christine L. Le Maitre, email: c.lemaitre@shu.ac.uk \\ Keywords: nucleus pulposUs, phenotypic markers, regeneration, stem cells PAX1, FOXF1, Pathology Section \\ Received: October 15,2015 Accepted: December 22, $2015 \quad$ Published: December 28, 2015
}

\section{ABSTRACT}

Progress in mesenchymal stem cell (MSC) based therapies for nucleus pulposus (NP) regeneration are hampered by a lack of understanding and consensus of the normal NP cell phenotype. Despite the recent consensus paper on NP markers, there is still a need to further validate proposed markers. This study aimed to determine whether an NP phenotypic profile could be identified within a large population of mature NP samples.

qRT-PCR was conducted to assess mRNA expression of 13 genes within human non-degenerate articular chondrocytes (AC) $(n=10)$ and NP cells extracted from patients across a spectrum of histological degeneration grades $(n=71)$. qRT-PCR results were used to select NP marker candidates for protein expression analysis.

Differential expression at mRNA between AC and non-degenerate NP cells was only observed for Paired Box Protein 1 (PAX1) and Forkhead box F1 (FOXF1). In contrast no other previously suggested markers displayed differential expression between non-degenerate NP and AC at mRNA level. PAX1 and FOXF1 protein expression was significantly higher in the NP compared to annulus fibrosus (AF), cartilaginous endplate (CEP) and AC. In contrast Laminin-5 (LAM-332), Keratin-19 (KRT-19) and Hypoxia Inducible Factor 1 alpha (HIF1a) showed no differential expression in NP cells compared with AC cells.

A marker which exclusively differentiates NP cells from AF and AC cells remains to be identified, raising the question: is the NP a heterogeneous population of cells? Or does the natural biological variation during IVD development, degeneration state and even the life cycle of cells make finding one definitive marker impossible?

\section{INTRODUCTION}

Low back pain (LBP) is one of the most prevalent health problems in the western world [1, 2], with degeneration of the intervertebral disc (IVD) implicated in $40 \%$ of cases [3, 4]. Current surgical treatments have been directed towards alleviating patient symptoms[5] but can accelerate degenerative changes in adjacent discs and have poor outcomes [6,7]. New approaches in tissue engineering have provided a variety of potential treatment options [8]. However current progress in MSC based therapies are hampered by a lack of understanding and consensus of the normal nucleus pulposus (NP) cell phenotype [9]. Considerable progress in understanding the ontogeny and physiology of NP cells has occurred over the last decade with a resultant plethora of marker genes identified to distinguish NP from annulus fibrosus (AF) and articular chondrocytes (AC) [9-14]. Risbud et al., (2015) recently reported NP phenotypic markers recommended for use in directing MSC based regeneration strategies for the NP [9]; this paper focused on defining the young healthy NP cell phenotype, as they hypothesised this cell type would be most successful in terms of NP regeneration as a treatment strategy for LBP [9]. However, despite this consensus paper, there is still a need to further validate, at gene and protein level, proposed NP markers 
which have been identified from transcription expression profiles or assessed at protein level but only in a small number of human samples; such molecules include: paired box protein 1 (PAX1), forkhead box f1 (FOXF1) [10, 15] and ovostatin-2 (OVO-2) [10] as well as the proposed NP negative marker Integrin binding sialoprotein (IBSP) [10], shown to be differentially expressed between NP and AC cells. Moreover the potential for matrix binding proteins to act as indicators of the NP ECM warrant further investigation. Namely laminin-332 (laminin-5) and laminin-511 (laminin 10) which have been previously shown to be expressed highly in rat and porcine NP tissue in comparison to annulus fibrosus (AF) tissue, however to date this has not been investigated in human IVD tissue $[16,17]$.

The aim of this study was to further validate the use of proposed NP specific markers on a large cohort of human NP and AC samples, at mRNA and protein level using qRT-PCR and immunohistochemistry. To determine whether an NP phenotypic profile could be identified within a large population of mature NP samples.

\section{RESULTS}

\section{qRT-PCR analysis}

Previously identified 'marker' genes $\mathrm{SHH}$, Brachyury, GLUT-1, CA12, KRT18, KRT19, CD24 (Figure 1), FOXF1, PAX1, LAM-511 (identified by $\alpha 5$ ) LAM-332 (identified by $\gamma 2$ ), OVO-2 as well as IBSP (Figure 2), a proposed negative NP marker, were assessed for mRNA expression using qRT-PCR. No significant difference in the levels of mRNA expression were observed between AC compared with non-degenerate NP cells with the exception of PAX1 and FOXF1 (Figures 1 \& 2).

The proportion of samples found to be expressing KRT-18 was significantly lower $(\mathrm{P}=0.0099)$ in AC samples compared with NP samples (Figure 1). The proportion of samples found to be expressing LAM-A5 was also significantly higher in moderate $(4-7)(\mathrm{P}=0.0086)$ and severely degenerate NP cells $(>7)(\mathrm{P}=0.0171)$ in comparison to AC cells $(\mathrm{P}=0.0317)$ (Figure 2). The notochordal markers $\mathrm{SHH}$ and brachyury were expressed in a small proportion of NP samples, with no expression detected in the non-degenerate $(<4)$ NP sample cohort (Figure 1). The proportion of samples found to be positive for IBSP mRNA expression was significantly higher $(\mathrm{P}=0.0263)$ in moderately degenerate (4-7) NP samples compared with AC samples (Figure 2). PAX1 and FOXF1 showed significantly higher expression levels in NP cells in comparison to AC cells ( $\mathrm{PAX} 1: \mathrm{P}=0.0003)$ (FOXF1: $\mathrm{P}=0.0049$ ) accompanied by a significantly higher proportion of samples (PAX1: $\mathrm{P}=0.0024)$ (FOXF1:
$\mathrm{P}=0.0067)$ in NP samples compared with AC samples, regardless of degeneration grade (Figure 2).

\section{Differential protein expression within the anatomical regions of the IVD}

KRT-19 protein was expressed at low levels throughout all anatomical regions of the IVD and was significantly higher in in the NP in comparison to the CEP $(\mathrm{P} \leq 0.05)$ (Figures $3 \& 4)$. LAM-5 (LAM-332) protein expression was detected in all regions with significantly higher expression levels in the NP $(\mathrm{P}=0.0001)$ and AF $(\mathrm{P}=0.0001)$ in comparison to the CEP, however no significant difference in the expression of LAM-5 protein was observed between the AF and NP (Figures $3 \& 4$ ). PAX1 and FOXF1 protein were expressed in all regions of the IVD and were significantly higher in the AF (PAX: $\mathrm{P}=0.0001$; FOXF1: $\mathrm{P}=0.003$ ) and NP (PAX: $\mathrm{P}=0.0001$; FOXF1: $\mathrm{P}=0.0001$ ) in comparison to the CEP and also significantly higher in the NP (PAX: $\mathrm{P}=0.0001$; FOXF1: $\mathrm{P}=0.0001$ ) compared to the AF (Figures $3 \& 4$ ).

\section{Immunohistochemical validation of NP marker genes in human $\mathrm{AC}$ and NP samples}

Within surgical samples PAX1 and FOXF1 protein was expressed in $100 \%$ of NP samples and $60 \%$ of AC (PAX1) and $80 \%$ of AC (FOXF1) samples (Figures $5 \&$ $6)$. The expression of PAX1 and FOXF1 was significantly higher in NP samples in comparison to AC samples regardless of grade of degeneration $(\mathrm{P} \leq 0.05)$ (Figure 6). $\mathrm{HIF} 1 \alpha$ protein was expressed in $100 \%$ of NP and AC samples (Figure 6). No significant difference in the protein expression of HIF $1 \alpha$ was observed between AC and NP samples (Figure 6).

\section{DISCUSSION}

\section{NP markers indicative of NP ontongeny}

The origin of NP cells is currently an unresolved area of IVD research. Compelling evidence indicates that mature NP cells of the adult IVD have differentiated along the notochordal lineage [30], however existing evidence which supports the migration of CEP and AF cells should not be ignored [31, 32]. The notochordal origin is reflected in the recommended markers $\mathrm{SHH}$ and brachyury expressed in the developing notochord [3335]. Decreased SHH and brachyury expression have been shown to correlate with aging and degeneration which agrees with the low proportion of samples expressing SHH and brachyury in this study, which could be due to the age of patient samples enrolled in this study (20- 

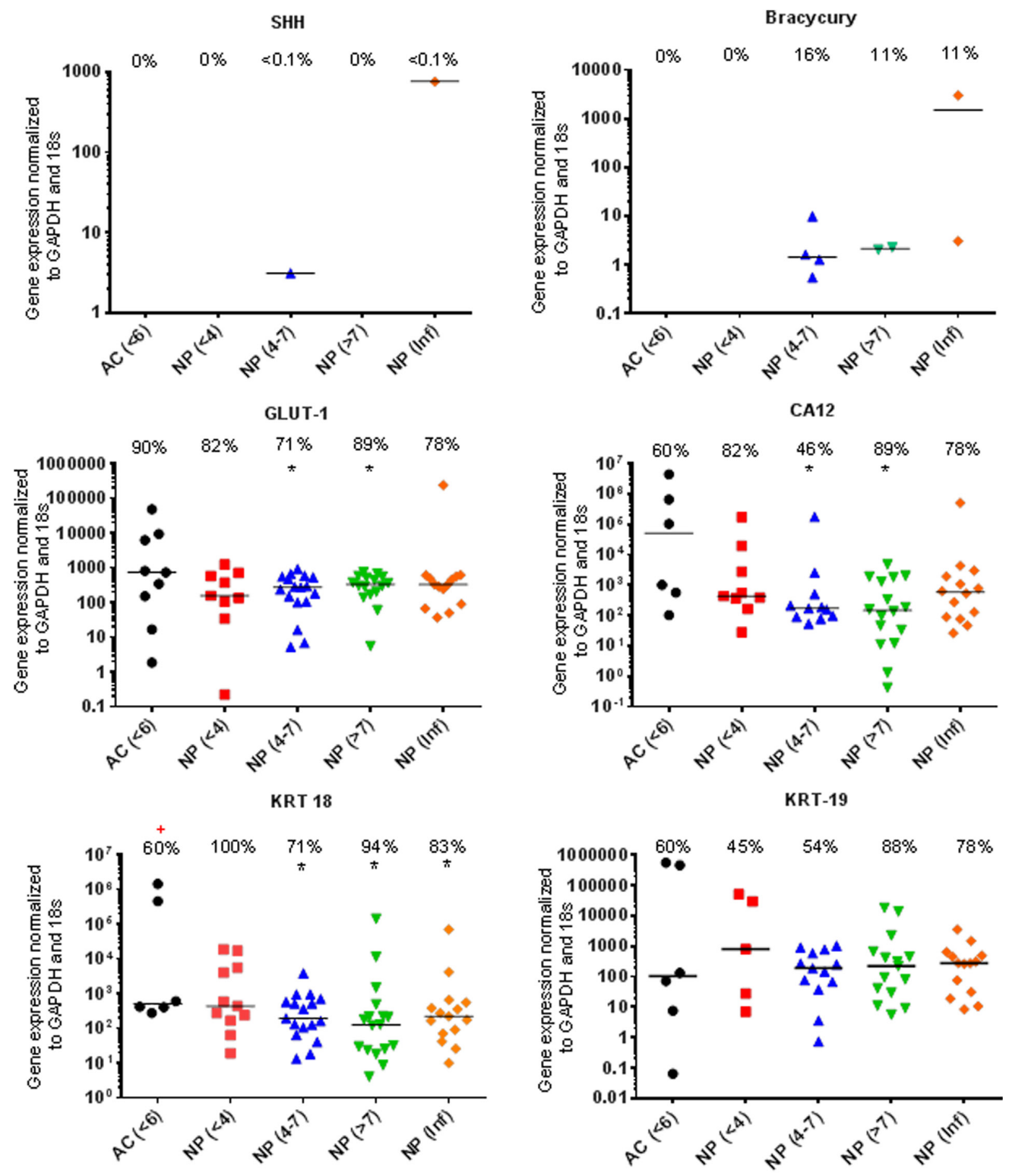

CD24

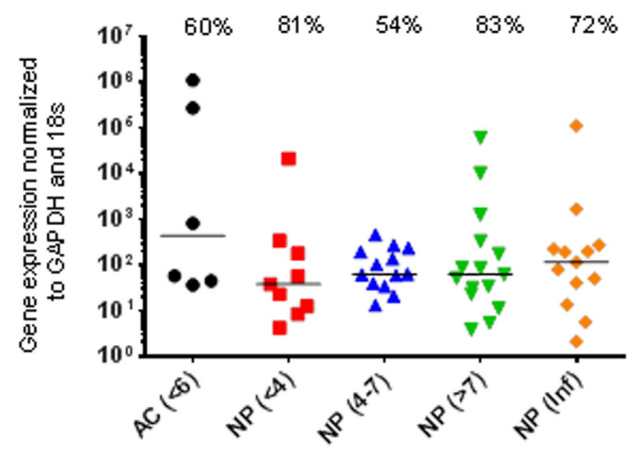

Figure 1: Markers recommended for use in defining the young healthy NP phenotype. qRT-PCR mRNA expression from directly extracted articular chondrocytes (AC), histologically non degenerate $(<6)$ and directly extracted nucleus pulposus (NP) cells, graded histologically as non-degenerate $(<4)$; moderately degenerate (4-7); severely degenerate $(>7)$ and those containing infiltrated cells (Inf). Percentage of positive samples displayed above. $\left(^{*}\right)$ significant difference in expression levels between AC and NP cells. (+) Significant difference in proportion of samples expressing target gene in NP samples compared to AC samples: $P=\leq 0.05$. 
71yrs).[36] Recently, however Wnt mediated reactivation of SHH signalling has been shown to increase expression of brachyury, aggrecan and chondroitin sulphate in aged discs [37]. Expression of brachyury has also been reported in the mature NP $[11,36]$. The lack of notochordal cells within the mature healthy adult NP must be considered when developing regenerative treatment strategies for IVD degeneration, since transplanted cells need to be capable of withstanding the altered microenvironmental cues in the mature NP. An ideal phenotypic NP marker would be one which is NP specific, reflects NP ontogeny and is consistently expressed in healthy mature NP cells, which populate and survive in the adult IVD. Having said this, using markers which reflect NP ontogeny, to inform differentiation of regenerative cells into NP cells is likely to be problematic since a lack of expression of
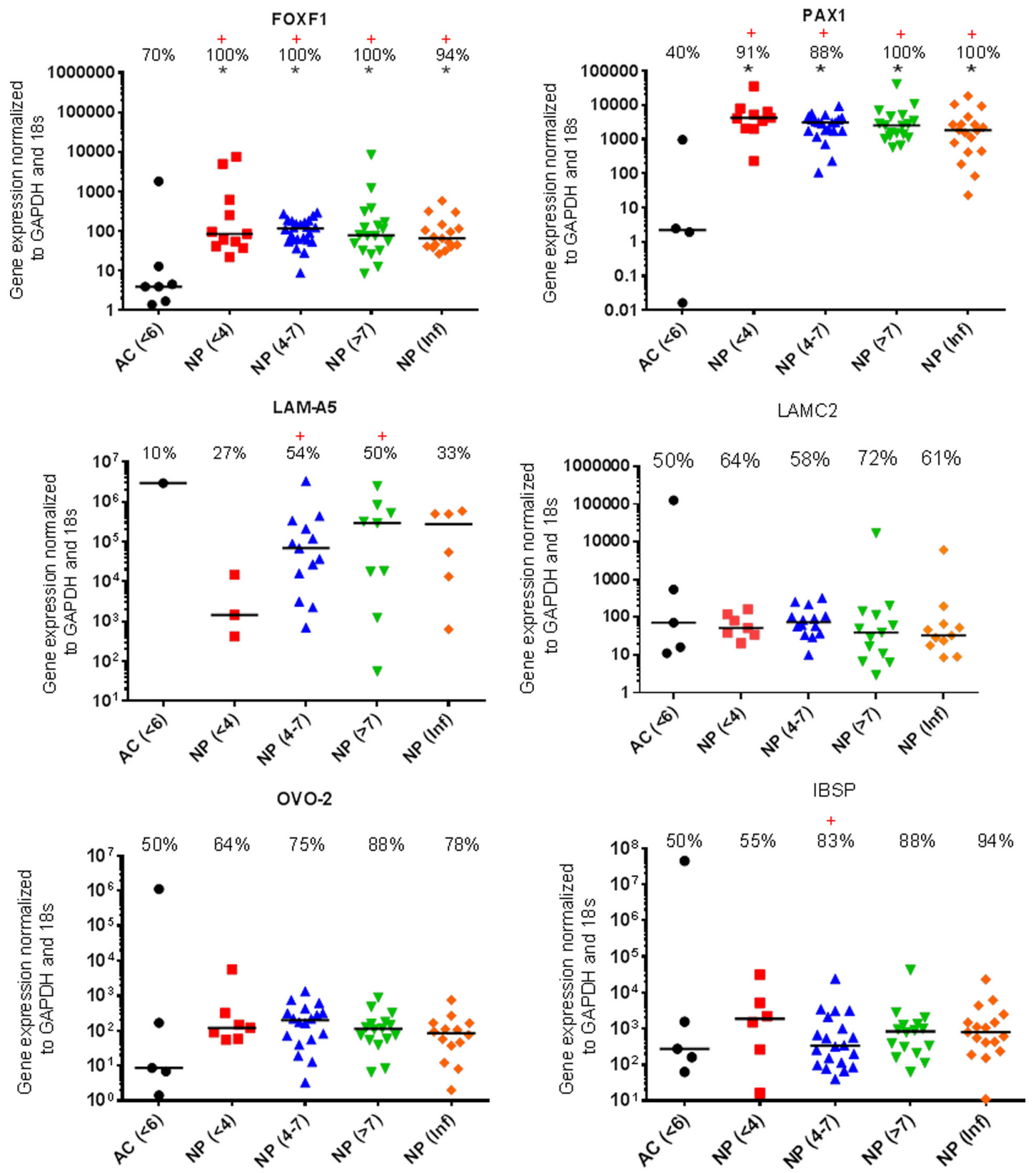

Figure 2: Proposed NP markers for further investigation. qRT-PCR mRNA expression from directly extracted articular chondrocytes $(\mathrm{AC})$, histologically non degenerate $(<6)$ and directly extracted nucleus pulposus $(\mathrm{NP})$ cells, graded histologically as nondegenerate $(<4)$; moderately degenerate (4-7); severely degenerate $(>7)$ and those containing infiltrated cells (Inf). Percentage of positive samples displayed above. $(*)$ significant difference in expression levels between AC and NP cells. ( + ) Significant difference in proportion of samples expressing target gene in NP samples compared to AC samples: $P=\leq 0.05$. 
such markers does not necessarily demonstrate that the regenerative cells being used are not differentiating into NP cells, it may simply demonstrate that the regenerative cells are not from the same ontogeny as NP cells.

\section{NP markers indicative of NP physiology}

The NP is the largest avascular tissue in the human body and thus NP cells are physiologically adapted to survive in a hypoxic microenvironment, mediated by the expression of HIF $1 \alpha[27,29,38]$. HIF-1 $\alpha$ drives glycolytic metabolism and supports the function and survival of NP cells by inducing the up-regulation of GAPDH, GLUT1/3, galectin-3, glucuronyltransferase-1 and vascular endothelial growth factor-A (VEGF-A) [28, 29]. GLUT-1 in particular, has been included alongside HIF $1 \alpha$ as a recommended marker, reflective of NP physiology $[9,14]$. However no differential expression was observed between AC and NP cells for GLUT1 or HIF1 $\alpha$. Similarly CA12, a physiological marker which reflects the ability of NP cells to buffer the elevated lactic acid found in

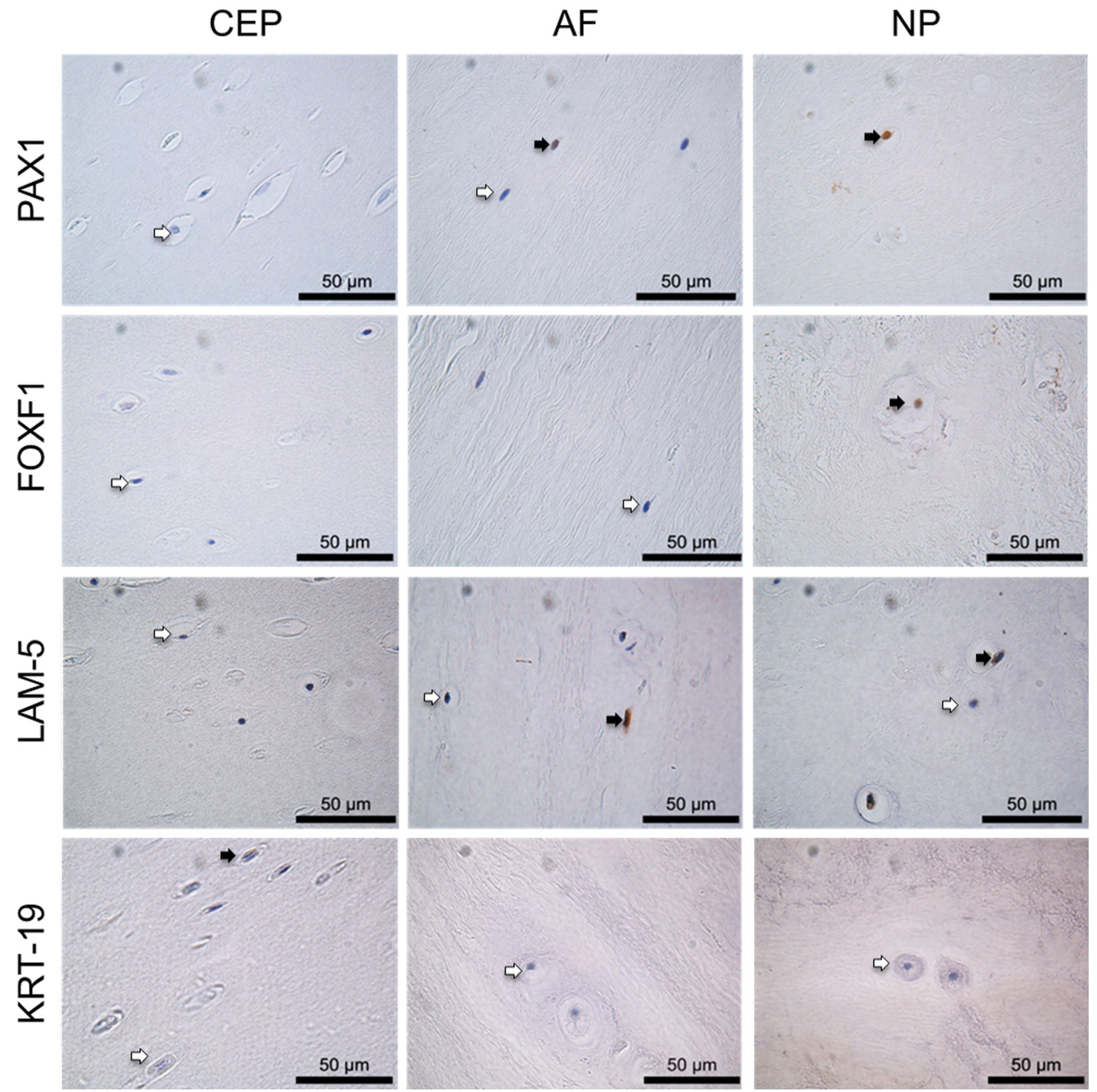

Figure 3: Immunohistochemistry of post mortem intervertebral disc samples. IHC of PAX1, FOXF1, LAM-5 and KRT-19 on post mortem samples, CEP (cartilaginous end plate), AF (annulus fibrosus) and NP (nucleus pulposus). Positive cells indicated by black arrows, negative cells indicated by white arrows. Scale bar $50 \mu \mathrm{m}$. 

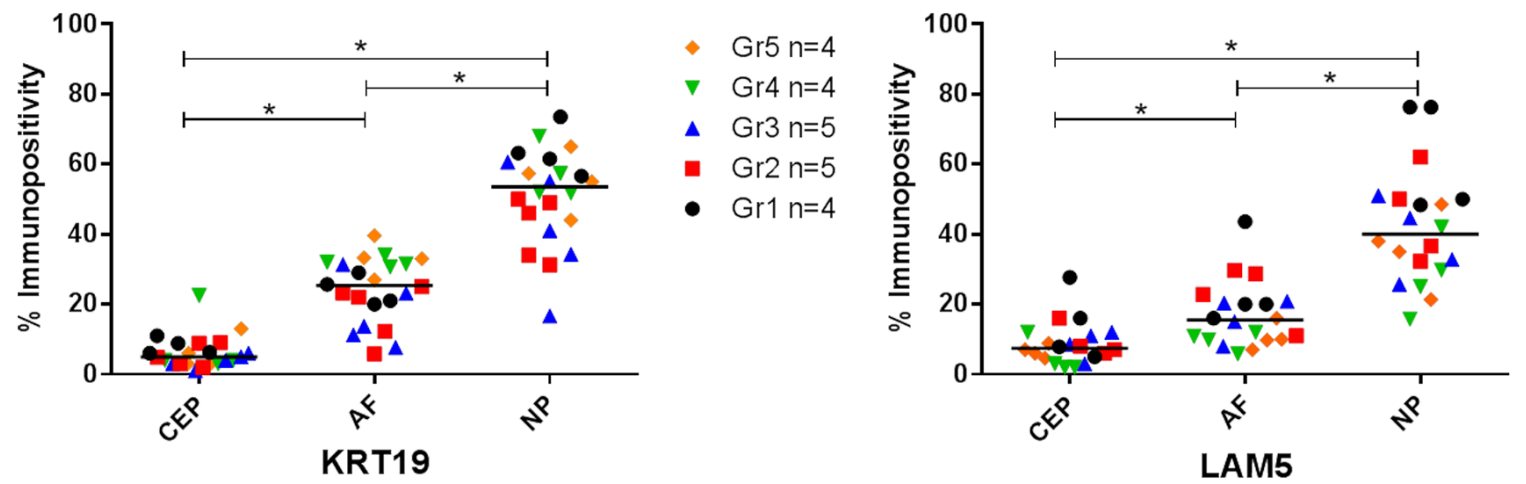

- Gr5 n=4

- Gr4 n=4

- Gr3 n=4

- Gr2 n=4

- $\mathrm{Gr} 1 \mathrm{n}=4$
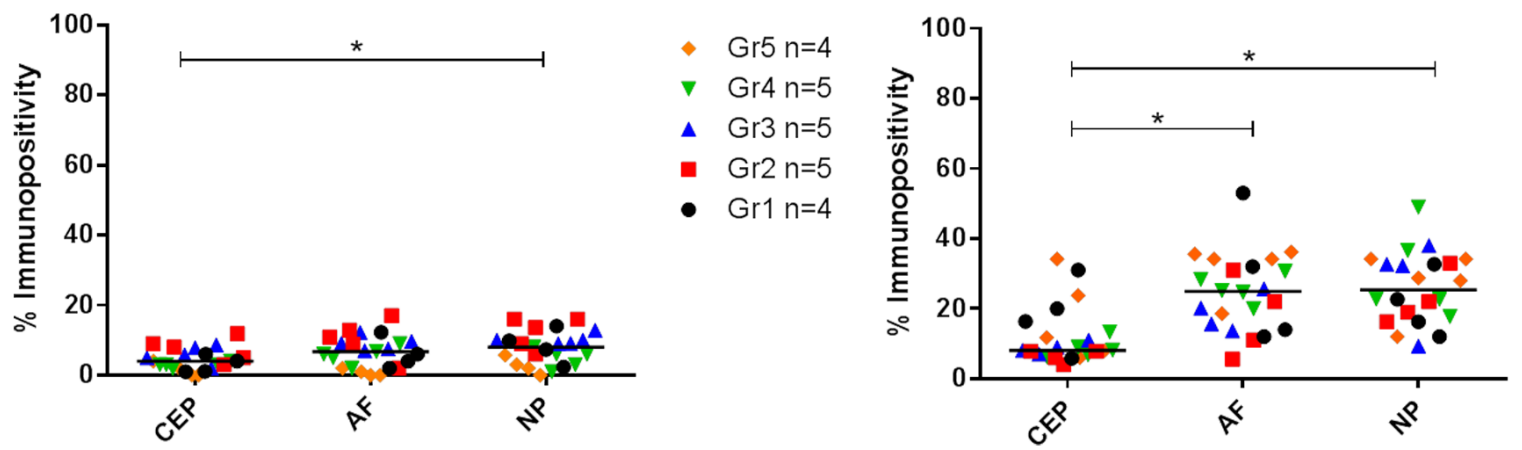

- Gr5 n $=5$

- Gr4 n=5

- $\mathrm{Gr} 3 \mathrm{n}=4$

- $\mathrm{Gr} 2 \mathrm{n}=4$

- $\mathrm{Gr} 1 \mathrm{n}=4$

Figure 4: Immunopositive quantification of post mortem intervertebral disc samples. Thompson grades 1-5. 200 cells counted per anatomical region and \% immunopositivity calculated. (*) Significance indicated between expression levels $P \leq 0.05$.
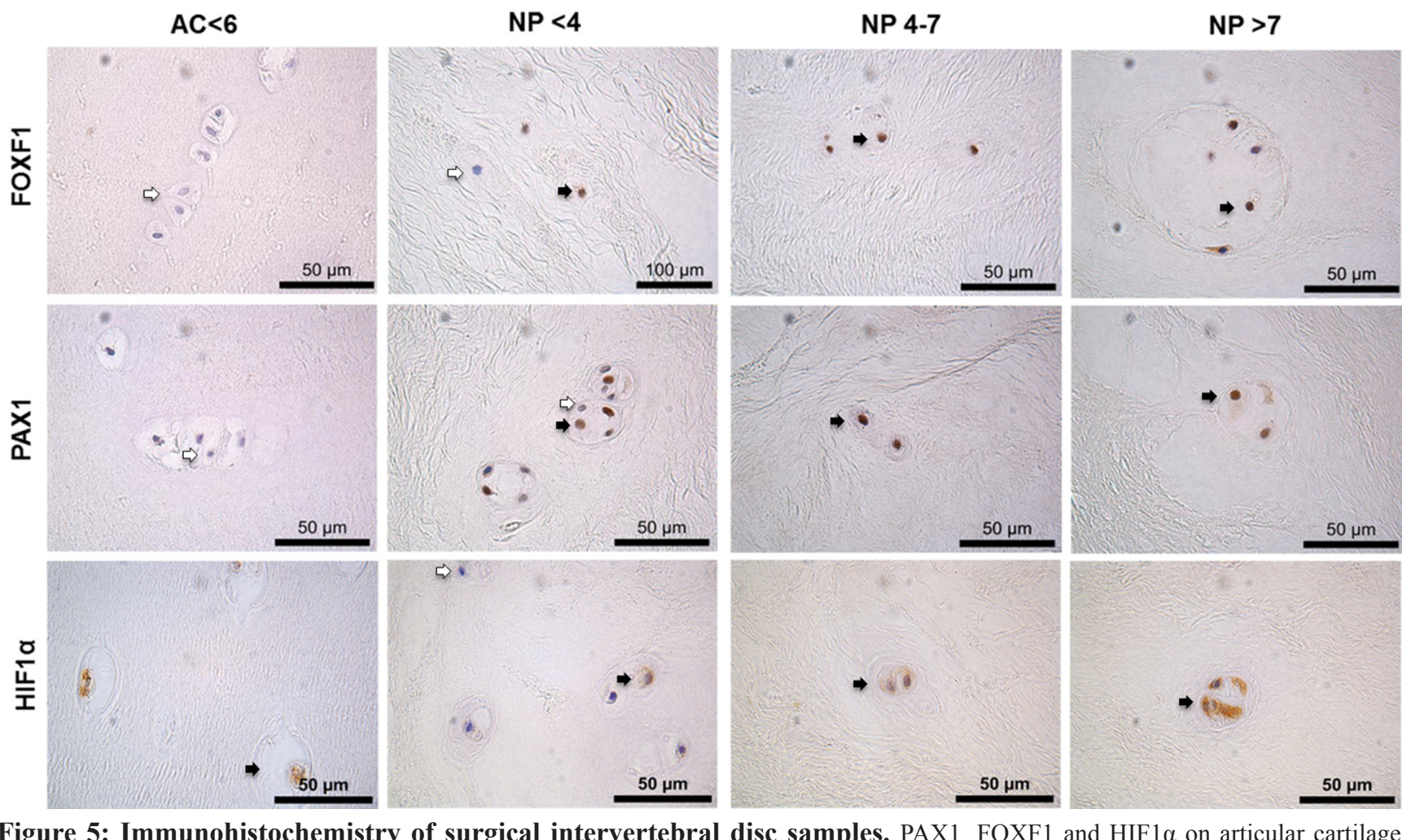

Figure 5: Immunohistochemistry of surgical intervertebral disc samples. PAX1, FOXF1 and HIF1 $\alpha$ on articular cartilage (AC) histologically graded as non-degenerate $(<6)$ and nucleus pulposus (NP) tissue surgically removed following discectomy graded histologically as non-degenerate $(<4)$; moderately degenerate (4-7) and severely degenerate $(>7)$. Positive cells indicated by black arrows, negative cells indicated by white arrows. Scale bar $50 \mu \mathrm{m}$. 
this tissue, [39] was also expressed in AC and NP cells with no significant difference in expression levels. Akin to the NP, AC is an avascular, hypoxic environment [40], and HIF-1 $\alpha$ is crucial for AC cell survival [41]. Thus, although physiological markers are essential to assess the ability of differentiated cells to respond appropriately to the harsh NP microenvironment, they are not NP specific. Interestingly however NP cells uniquely constitutively express HIF $1 \alpha$ even in the presence of oxygen [27]. NP cell differentiation assessment could focus on constitutive HIF $1 \alpha$ expression under hypoxic and normoxic culture conditions as opposed to simply expression of the protein.

\section{Differentially expressed markers recommended for use in defining the NP phenotype}

Microarray studies by Fujitta et al., 2005 identified the expression of the heat-stable antigen CD24, in rat NP cells, which was later replicated in subsequent studies [42, 43]. Despite this, differential expression of CD24 was not confirmed in human samples in this study, in agreement with Rutges et al., 2010 who reported that CD24 was not differentially expressed [12]. KRT-18 (canine) and KRT-19 (rat) were also identified as differentially expressed between NP and AC cells [25], which was confirmed in bovine IVDs [11]. However, these results failed to translate to human samples in this study with no significant difference observed. KRT-19 is expressed in the embryonic notochord [44] and has been shown to decrease with age [12] which could explain the differential results in this study. Although KRT-18 was seen in human NP samples $67 \%$ of AC samples also showed expression, thus the use of this marker alone lacks NP specificity.

\section{Differentially expressed markers between NP and $\mathrm{AC}$ which require further investigation}

A multitude of proposed genes have been identified as NP phenotypic markers, those which are less well validated include the OVO-2[10], FOXF1 [10, 15] and PAX1 [10, 15]. Additionally LAM-332 (LAM-5) and LAM-511 (LAM-10) have recently been shown to be differentially expressed between porcine and rat NP and AF [17]. Furthermore it may also be useful to include NP negative, AC positive markers in a panel which assesses the phenotypic profile of differentiating cells to NP-like cells, such as IBSP [10]. Unlike previous studies OVO2, LAM-511 (identified by the $\alpha 5$ subunit), LAM-332 (identified by the ${ }_{\gamma} 2$ chain), and IBSP were not differentially expressed at mRNA level between NP and $\mathrm{AC}$ in human samples. The higher protein expression of LAM-5 in NP compared to AF reported previously[16] was not replicated in human samples in this study, however the LAM-5 antibody used recognises the $\alpha 3$ subunit and thus may also recognise LAM-6/7. A variety of studies have published conflicting data on marker genes proposed as being differentially expressed between NP and $\mathrm{AC}$; this could be due to species variation and/or small sample sizes.

Previously reported novel NP marker genes, PAX1 and FOXF1 were validated by qRT-PCR and immunohistochemistry as being more highly expressed in the NP than AC $[10,15]$. Interestingly, protein expression of PAX1 and FOXF1 were also higher in NP than both AF and the CEP, shown here for the first time in native tissue; supported recently by Van den Akker et al., 2014, where human NP and AF cell populations were extracted from non-degenerate healthy IVDs and were shown to express PAX1 and FOXF1 more highly in extracted NP compared to AF cells [15]. Higher expression of FOXF1 in NP cells
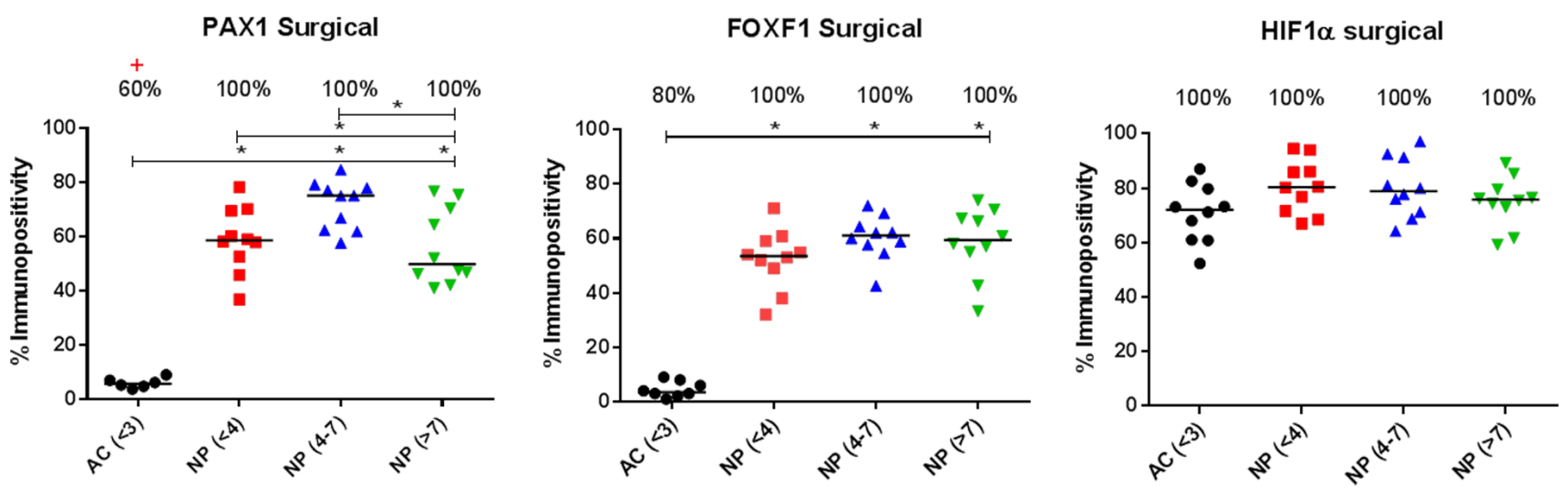

Figure 6: Immunopositive quantification of surgical intervertebral disc samples. Immunohistochemistry of PAX1, FOXF1 and HIF $1 \alpha$ on articular cartilage (AC) histologically non degenerate $(<6)$ and nucleus pulposus (NP) tissue graded histologically as nondegenerate $(<4)$; moderately degenerate $(4-7)$ and severely degenerate $(>7)$. Percentage of positive samples displayed above. $(*)$ indicates significance between \% immunopositivity of NP compared to AC. $(+)$ Indicates significance between proportion of NP samples found to be expressing target protein, compared to AC samples $P=\leq 0.05$. 
compared to $\mathrm{AC}$ cells has been previously reported [10, 15], but the exact role of FOXF1 in the human IVD is yet to be elucidated. The role of FOXF1 in cell proliferation, differentiation and cell survival is well established[45-47]. FOXF1 gene deletions have been associated with birth defects including spinal malformations and fusion of the vertebrae [48]. PAX1 expression in the IVD has been previously reported in young adult mice [49], in the human fetal vertebral column [50] and in the human NP [10], however, the exact role of PAX1 within the NP is unknown.

Both PAX1 and FOXF1 can be activated by SHH signalling. [51] PAX1 is regulated by SHH signalling and is often used to illustrate continued SHH signalling in sclerotome development [52]. While SHH is not necessary for the induction of PAX1, SHH knockout mice lack vertebral structures and quickly lose PAX1 expression [53], thus, the loss of SHH expression in mature adult NP cells could alter the expression of PAX1 in human NP cells. Although PAX1 expression has previously been associated as a marker of sclerotomal cells and is highly expressed in the AF, shown in mouse models [49, 54], studies which assess the expression of PAX1 and FOXF1 during human IVD development and in the different anatomical regions of the IVD are lacking. Whether the high expression of PAX1 and FOXF1 shown here in mature human NP cells reflects NP cell ontogeny, possible migration of cells from adjacent tissues, or is a functional marker of mature adult NP cells, remains to be elucidated. Despite limited understanding of the role of PAX1 and FOXF1 in the human NP, this study demonstrated differential expression by NP cells which did not increase with degeneration grade; thus the exact role of PAX1 and FOXF1 within the NP warrants further investigation and both should be considered for use in defining the adult NP cell phenotype. Noteworthy, however is the fact that although expression levels were higher in NP cells, AC and AF cells were shown to express PAX1 and FOXF1; thus it is vital that such molecules are only used within a panel of NP markers thus providing a phenotypic profile which reflects the ontogeny, physiology and function of NP cells.

\section{CONCLUSIONS}

A marker which exclusively differentiates NP cells from $\mathrm{AF}$ and $\mathrm{AC}$ cells remains to be identified, raising the question: is the NP a heterogeneous population of cells? Or does the natural biological variation during IVD development, degeneration state and even the life cycle of cells make finding one definitive marker impossible? From a clinical perspective the aim is to restore/maintain spine biomechanics and alleviate patient symptoms; thus the ability of differentiated cells to recapitulate the NP ECM (aggrecan to collagen type II ratio $>20$ ) and NP biomechanics should be the prime focus when developing treatment strategies for regeneration of the IVD, as opposed to the expression of NP phenotypic markers.

\section{MATERIALS AND METHODS}

\section{Human IVD tissue}

Human IVD tissue was obtained from surgery or PM examination (processed within 72 hours after death) with informed consent of the patients or relatives. Ethical approval was obtained from Sheffield Research Ethics Committee (09/H1308/70), and department of Pathology/ UMCU Biobank, UMC Utrecht (Supplementary Table I/ II).

\section{Human articular cartilage tissue}

Human articular cartilage (AC) samples were obtained from patients undergoing total knee replacement surgery with informed consent of the patient or relatives (Supplementary Table III). Cartilage was obtained under the National Research Ethics Service approval held by the Sheffield Musculoskeletal Biobank. AC was obtained from various anatomical compartments within the knee (medial and lateral tibio-femoral and patello-femoral compartments) for 10 surgical AC samples. Cartilage tissue was graded macroscopically $0-4$ using the Outerbridge classification [18]. All AC samples used in this study were macroscopically graded as non-degenerate (grade 0-1).

\section{Tissue processing}

\section{IVD tissue}

IVD tissues processed at Sheffield Hallam University (SHU) were separated into two and either fixed in $10 \%$ neutral buffered formalin (Leica, Milton Keynes UK) and processed to paraffin wax (Leica) or processed for cell extraction. Following paraffin wax embedding, $4 \mu \mathrm{m}$ sections were cut, mounted onto positively charged slides (Leica) and IVD tissue histologically graded using previously published criteria $[19,20]$. NP tissue free from contaminating $\mathrm{AF}$ and $\mathrm{CEP}$ was digested in protease and collagenase to isolate cells and RNA extracted as previously published [21]. IVD Tissue processed at Utrecht was decalcified and embedded to paraffin wax as previously published [22]. Four micron sections were histologically graded using previously published criteria $[19,20]$.

\section{AC tissue}

AC tissue was separated into two and either fixed in $10 \% \mathrm{v} / \mathrm{v}$ neutral buffered formalin (Leica) and processed 
to paraffin wax, or processed for cell extraction. Following paraffin wax embedding, $4 \mu \mathrm{m}$ sections were histologically graded based on the Mankin [23] grading system with the addition of abnormal features and cartilage thickness also assessed. Cells were extracted using trypsin and collagenase as previously published [24], and cells were used for direct RNA extraction using TRIZOL reagent and cDNA synthesised.

\section{Real-time quantitative polymerise chain reaction (qRT-PCR)}

Target genes were investigated using quantitative real-time polymerase chain reaction (qRT-PCR) conducted on 10 non-degenerate AC samples (microscopic grade 0-6), 11 non-degenerate NP samples (grade <4), 24 moderately degenerate NP samples (grade 4 -7), 18 severely degenerate NP samples (grade $>7$ ) and 18 NP samples with evident infiltration (Supplementary Table I, II, III).

qRT-PCR was performed on a StepOnePlus ${ }^{\text {TM }}$ RealTime PCR System (Applied Biosystems, Lutterworth UK) for potential NP markers (Pre-designed primer/ probe mixes Applied Biosystems) (Supplementary Table IV). Glyceraldehyde-3-phosphate dehydrogenase (GAPDH) and 18S (Applied Biosystems) were used as housekeeping genes. Ten microliter reactions were prepared using TaqMan Universal PCR Master Mix (Applied Biosystems). Results were analysed using the $2^{-\Delta \mathrm{Ct}}$ method and presented as relative gene expression normalised to the average $\mathrm{C}_{\mathrm{T}}$ for the two housekeeping genes.

\section{Immunohistochemistry}

Immunohistochemistry (IHC) was conducted on PM samples from the department of Pathology/ UMCU Biobank, UMC Utrecht, Thompson grades $1-5(n=4 / 5)$ to assess protein expression within each of the anatomical regions (CEP, AF, NP) of the IVD. IHC analysis was undertaken for PAX1 and FOXF1, found to be differentially expressed at gene level (Figure 2), KRT19 due to its extensive use as an NP marker in a variety of studies [10, 12, 25] and LAM-5 (LAM-332) to determine whether the differential expression observed between NP and $\mathrm{AF}$ in porcine tissue correlated with human tissue [16, 17]. Further IHC analysis of PAX1 and FOXF1, shown to be differentially expressed within the NP compared to both the AF and CEP (Figures $3 \& 4$ ) and HIF1 $\alpha$ shown to be essential to the physiology of NP cells and regulated at protein level [26-29], was conducted on a larger subset of surgical samples (NP: $n=30 ; A C: n=10$ ) (Supplementary Table I/III) to investigate differential expression between $\mathrm{NP}$ and $\mathrm{AC}$ tissue.

Sections were prepared as described for histological analysis; IHC was performed as previously described, [19] specific antigen retrieval, serum block, and antibody details shown in Supplementary Table V. All slides were visualised using an Olympus BX51 microscope and images captured by digital camera and Capture Pro OEM v8.0 software (Media Cybernetics, Buckinghamshire, UK). Evaluation of IHC staining was performed by counting 200 cells within each anatomical region (NP, AF, CEP or AC) on each section, with immunopositive cells expressed as a percentage of total count.

\section{Statistical analysis}

Data were shown to be non-parametric and hence a Kruskall-Wallis with Conover-Inman post hoc analysis test was used to identify significant differences between AC compared with NP samples, as well as differences between NP degeneration grade, investigated by qRTPCR and IHC $(P \leq 0.05)$. Two independent proportionality tests were performed to identify differences between the proportions of samples expressing the target molecules at mRNA and protein level $(P \leq 0.05)$.

\section{Abbreviations}

MSC, mesenchymal stem cell; LBP, low back pain; NP, nucleus pulposus; AF, annulus Fibrosus; CEP, cartilagenous endplate; $\mathrm{AC}$, articular chondrocyte; $\mathrm{SHH}$, sonic hedgehog; GLUT-1, glucose transporter 1; CA12, carbonic anhydrase XII; KRT18, Keratin 18; KRT19, Keratin 19; CD24, Cluster of differentiation 24; FOXF1, Forkhead Box F1; PAX1, Paired Box 1; LAMA5, Laminin Alpha 5; LAMC2, Laminin gamma 2; LAM5/332, Laminin 5/332; LAM10/511, Laminin, 10/511; OVO-2, Ovostatin 2; IBSP, Integrin Binding Sialoprotein; HIF $1 \alpha$, Hypoxia-inducible factor 1-alpha.

\section{ACKNOWLEDGMENTS}

We would like to offer kind thanks to A.A Cole, L.M Breakwell, A.L.R Michael, N. Chiverton and M.Wilkinson for providing samples. Articular cartilage tissue samples were supplied by the Sheffield Biorepository.

\section{CONFLICTS OF INTERESTS}

None declared.

\section{GRANT SUPPORT}

The authors would like to thank the Biomolecular Sciences Research Centre, Sheffield Hallam University for PhD studentship. 


\section{Authors' contributions}

AAT performed all laboratory work, data analysis and statistical analysis, contributed to study design and drafted the manuscript. ALB processed IVD tissues for cell extraction and cDNA synthesis and contributed to study design and contributed to manuscript preparation. LC provided PM IVD samples, contributed to study design and critically revised the manuscript. CS contributed to study design analysis of the data, helped to secure funding and critically revised the manuscript. CLLM conceived the study, participated in its design and coordination, aided in the analysis of data, secured funding and critically revised the manuscript. All authors read and approved the final manuscript.

\section{REFERENCES}

1. Hoy DG, Smith E, Cross M, Sanchez-Riera L, Blyth FM, Buchbinder R, Woolf AD, Driscoll T, Brooks P, March LM. Reflecting on the global burden of musculoskeletal conditions: lessons learnt from the global burden of disease 2010 study and the next steps forward. Annals of the Rheumatic Diseases. 2015; 74: 4-7.

2. Walker BF. The prevalence of low back pain: a systematic review of the literature from 1966 to 1998. Journal of Spinal Disorders \& Techniques. 2000; 13: 205-217.

3. Cheung KM, Karppinen J, Chan D, Ho DW, Song YQ, Sham P, Cheah KS, Leong JC, Luk KD. Prevalence and pattern of lumbar magnetic resonance imaging changes in a population study of one thousand forty-three individuals. Spine. 2009; 34: 934-940.

4. Livshits G, Popham M, Malkin I, Sambrook PN, Macgregor AJ, Spector T, Williams FM. Lumbar disc degeneration and genetic factors are the main risk factors for low back pain in women: the UK Twin Spine Study. Annals of the Rheumatic Diseases. 2011; 70: 1740-1745.

5. Le Maitre CL, Binch AL, Thorpe AA, Hughes SP. Degeneration of the intervertebral disc with new approaches for treating low back pain. Journal of neurosurgical sciences. 2015; 59: 47-61.

6. Eck JC, Humphreys SC, Lim TH, Jeong ST, Kim JG, Hodges SD, An HS. Biomechanical study on the effect of cervical spine fusion on adjacent-level intradiscal pressure and segmental motion. Spine. 2002; 27: 2431-2434.

7. Lund T, Oxland TR. Adjacent level disk disease-is it really a fusion disease?. Orthopedic Clinics of North America. 2011; 42: 529-541.

8. Thorpe A, Sammon C, Le Maitre C. Cell or Not to Cell'that is the Question: For Intervertebral Disc Regeneration. J Stem Cell Res Dev Ther. 2015; 2.

9. Risbud MV, Schoepflin ZR, Mwale F, Kandel RA, Grad S, Iatridis JC, Sakai D, Hoyland JA. Defining the phenotype of young healthy nucleus pulposus cells: Recommendations of the Spine Research Interest Group at the 2014 annual ORS meeting. Journal of Orthopaedic Research. 2015.

10. Minogue BM, Richardson SM, Zeef LA, Freemont AJ, Hoyland JA. Characterization of the human nucleus pulposus cell phenotype and evaluation of novel marker gene expression to define adult stem cell differentiation. Arthritis \& Rheumatism. 2010; 62: 3695-3705.

11. Minogue BM, Richardson SM, Zeef LA, Freemont AJ, Hoyland JA. Transcriptional profiling of bovine intervertebral disc cells: implications for identification of normal and degenerate human intervertebral disc cell phenotypes. Arthritis research \& therapy. 2010; 12: R22.

12. Rutges J, Creemers L, Dhert W, Milz S, Sakai D, Mochida J, Alini M, Grad S. Variations in gene and protein expression in human nucleus pulposus in comparison with annulus fibrosus and cartilage cells: potential associations with aging and degeneration. Osteoarthritis and Cartilage. 2010; 18: 416-423.

13. Rodrigues-Pinto R, Richardson SM, Hoyland JA. Identification of novel nucleus pulposus markers: Interspecies variations and implications for cell-based therapiesfor intervertebral disc degeneration. Bone $\&$ joint research. 2013; 2: 169-178.

14. Richardson S, Knowles R, Tyler J, Mobasheri A, Hoyland J. Expression of glucose transporters GLUT-1, GLUT3, GLUT-9 and HIF-1 $\alpha$ in normal and degenerate human intervertebral disc. Histochemistry and cell biology. 2008; 129: 503-511.

15. Van den Akker G, Surtel D, Cremers A, Rodrigues-Pinto R, Richardson SM, Hoyland JA, van Rhijn LW, Welting TJ, Voncken JW. Novel immortal human cell lines reveal subpopulations in the nucleus pulposus. Arthritis Res Ther. 2014; 16: R135.

16. Bridgen D, Gilchrist C, Richardson W, Isaacs R, Brown C, Yang K, Chen J, Setton L. Integrin-mediated interactions with extracellular matrix proteins for nucleus pulposus cells of the human intervertebral disc. Journal of Orthopaedic Research. 2013; 31: 1661-1667.

17. Gilchrist CL, Francisco AT, Plopper GE, Chen J, Setton LA. Nucleus pulposus cell-matrix interactions with laminins. European cells \& materials. 2011; 21: 523-532.

18. Cameron ML, Briggs KK, Steadman JR. Reproducibility and reliability of the outerbridge classification for grading chondral lesions of the knee arthroscopically. The American Journal of Sports Medicine. 2003; 31: 83-86.

19. Le Maitre CL, Freemont AJ, Hoyland JA. Localization of degradative enzymes and their inhibitors in the degenerate human intervertebral disc. The Journal of pathology. 2004; 204: 47-54.

20. Sive JI, Baird P, Jeziorsk M, Watkins A, Hoyland JA, Freemont AJ. Expression of chondrocyte markers by cells of normal and degenerate intervertebral discs. Molecular pathology : MP. 2002; 55: 91-97.

21. Wang H, Tian Y, Wang J, Phillips KL, Binch AL, Dunn 
S, Cross A, Chiverton N, Zheng Z, Shapiro IM, Le Maitre CL, Risbud MV. Inflammatory cytokines induce NOTCH signaling in nucleus pulposus cells: implications in intervertebral disc degeneration. The Journal of biological chemistry. 2013; 288: 16761-16774.

22. Kristensen HK. An improved method of decalcification. Biotechnic \& Histochemistry. 1948; 23: 151-154.

23. Altman R, Asch E, Bloch D, Bole G, Borenstein D, Brandt K, Christy W, Cooke T, Greenwald R, Hochberg M. Development of criteria for the classification and reporting of osteoarthritis: classification of osteoarthritis of the knee. Arthritis \& Rheumatism. 1986; 29: 1039-1049.

24. Dunn S, Wilkinson J, Crawford A, Le Maitre C, Bunning R. Cannabinoid WIN-55,212-2 mesylate inhibits interleukin- $1 \beta$ induced matrix metalloproteinase and tissue inhibitor of matrix metalloproteinase expression in human chondrocytes. Osteoarthritis and Cartilage. 2014; 22: 133144.

25. Lee CR, Sakai D, Nakai T, Toyama K, Mochida J, Alini M, Grad S. A phenotypic comparison of intervertebral disc and articular cartilage cells in the rat. European Spine Journal. 2007; 16: 2174-2185.

26. Merceron C, Mangiavini L, Robling A, Wilson TL, Giaccia AJ, Shapiro IM, Schipani E, Risbud MV. Loss of HIF$1 \alpha$ in the Notochord Results in Cell Death and Complete Disappearance of the Nucleus Pulposus. 2014.

27. Risbud MV, Guttapalli A, Stokes DG, Hawkins D, Danielson KG, Schaer TP, Albert TJ, Shapiro IM. Nucleus pulposus cells express HIF-1 $\alpha$ under normoxic culture conditions: A metabolic adaptation to the intervertebral disc microenvironment. Journal of cellular biochemistry. 2006; 98: 152-159.

28. Rajpurohit R, Risbud MV, Ducheyne P, Vresilovic EJ, Shapiro IM. Phenotypic characteristics of the nucleus pulposus: expression of hypoxia inducing factor-1, glucose transporter-1 and MMP-2. Cell and tissue research. 2002; 308: 401-407.

29. Agrawal A, Guttapalli A, Narayan S, Albert TJ, Shapiro IM, Risbud MV. Normoxic stabilization of HIF-1alpha drives glycolytic metabolism and regulates aggrecan gene expression in nucleus pulposus cells of the rat intervertebral disk. American journal of physiology.Cell physiology. 2007; 293: C621-31.

30. Risbud MV, Schaer TP, Shapiro IM. Toward an understanding of the role of notochordal cells in the adult intervertebral disc: from discord to accord. Developmental Dynamics. 2010; 239: 2141-2148.

31. Kim K, Ha K, Lee J, Nam S, Woo Y, Lim T, An HS. Notochordal cells stimulate migration of cartilage end plate chondrocytes of the intervertebral disc in in vitro cell migration assays. The Spine Journal. 2009; 9: 323-329.

32. Kim KW, Lim TH, Kim JG, Jeong ST, Masuda K, An HS. The origin of chondrocytes in the nucleus pulposus and histologic findings associated with the transition of a notochordal nucleus pulposus to a fibrocartilaginous nucleus pulposus in intact rabbit intervertebral discs. Spine. 2003; 28: 982-990.

33. Choi KS, Harfe BD. Hedgehog signaling is required for formation of the notochord sheath and patterning of nuclei pulposi within the intervertebral discs. Proceedings of the National Academy of Sciences of the United States of America. 2011; 108: 9484-9489.

34. Choi K, Lee C, Harfe BD. Sonic hedgehog in the notochord is sufficient for patterning of the intervertebral discs. Mechanisms of development. 2012; 129: 255-262.

35. Hotta K, Takahashi H, Satoh N, Gojobori T. Brachyurydownstream gene sets in a chordate, Ciona intestinalis: integrating notochord specification, morphogenesis and chordate evolution. Evolution \& development. 2008; 10: 37-51.

36. Smolders LA, Meij BP, Riemers FM, Licht R, Wubbolts R, Heuvel D, Grinwis G, Vernooij H, Hazewinkel HA, Penning LC. Canonical Wnt signaling in the notochordal cell is upregulated in early intervertebral disk degeneration. Journal of Orthopaedic Research. 2012; 30: 950-957.

37. Winkler T, Mahoney EJ, Sinner D, Wylie CC, Dahia CL. Wnt signaling activates shh signaling in early postnatal intervertebral discs, and re-activates shh signaling in old discs in the mouse. 2014.

38. Risbud MV, Schipani E, Shapiro IM. Hypoxic regulation of nucleus pulposus cell survival: from niche to notch. The American journal of pathology. 2010; 176: 1577-1583.

39. Power KA, Grad S, Rutges JP, Creemers LB, van Rijen MH, O'Gaora P, Wall JG, Alini M, Pandit A, Gallagher WM. Identification of cell surface-specific markers to target human nucleus pulposus cells: Expression of carbonic anhydrase XII varies with age and degeneration. Arthritis \& Rheumatism. 2011; 63: 3876-3886.

40. Cernanec J, Guilak F, Weinberg JB, Pisetsky DS, Fermor B. Influence of hypoxia and reoxygenation on cytokineinduced production of proinflammatory mediators in articular cartilage. Arthritis \& Rheumatism. 2002; 46: 968975.

41. Schipani E, Ryan HE, Didrickson S, Kobayashi T, Knight M, Johnson RS. Hypoxia in cartilage: HIF- 1alpha is essential for chondrocyte growth arrest and survival. Genes \& development. 2001; 15: 2865.

42. Fujita N, Miyamoto T, Imai J, Hosogane N, Suzuki T, Yagi M, Morita K, Ninomiya K, Miyamoto K, Takaishi H. CD24 is expressed specifically in the nucleus pulposus of intervertebral discs. Biochemical and biophysical research communications. 2005; 338: 1890-1896.

43. Sakai D, Nakamura Y, Nakai T, Mishima T, Kato S, Grad S, Alini M, Risbud MV, Chan D, Cheah KS. Exhaustion of nucleus pulposus progenitor cells with ageing and degeneration of the intervertebral disc. Nature communications. 2012; 3: 1264.

44. Götz W, Kasper M, Fischer G, Herken R. Intermediate 
filament typing of the human embryonic and fetal notochord. Cell and tissue research. 1995; 280: 455-462.

45. Ormestad M, Astorga J, Landgren H, Wang T, Johansson BR, Miura N, Carlsson P. Foxf1 and Foxf2 control murine gut development by limiting mesenchymal Wnt signaling and promoting extracellular matrix production. Development (Cambridge, England). 2006; 133: 833-843.

46. Mahlapuu M, Ormestad M, Enerback S, Carlsson P. The forkhead transcription factor Foxf1 is required for differentiation of extra-embryonic and lateral plate mesoderm. Development (Cambridge, England). 2001; 128: 155-166.

47. Kalinichenko VV, Zhou Y, Bhattacharyya D, Kim W, Shin B, Bambal K, Costa RH. Haploinsufficiency of the mouse Forkhead Box f1 gene causes defects in gall bladder development. The Journal of biological chemistry. 2002; 277: 12369-12374.

48. Stankiewicz P, Sen P, Bhatt SS, Storer M, Xia Z, Bejjani BA, Ou Z, Wiszniewska J, Driscoll DJ, Bolivar J. Genomic and genic deletions of the FOX gene cluster on 16q24. 1 and inactivating mutations of FOXF1 cause alveolar capillary dysplasia and other malformations. The American Journal of Human Genetics. 2009; 84: 780-791.

49. DiPaola CP, Farmer JC, Manova K, Niswander LA. Molecular signaling in intervertebral disk development. Journal of orthopaedic research. 2005; 23: 1112-1119.

50. Smith CA, Tuan RS. Functional involvement of Pax1 in somite development: Somite dysmorphogenesis in chick embryos treated with Pax-1 paired-box antisense oligodeoxynucleotide. Teratology. 1995; 52: 333-345.

51. Madison BB, McKenna LB, Dolson D, Epstein DJ, Kaestner KH. FoxF1 and FoxL1 link hedgehog signaling and the control of epithelial proliferation in the developing stomach and intestine. The Journal of biological chemistry. 2009; 284: 5936-5944.

52. Murtaugh LC, Chyung JH, Lassar AB. Sonic hedgehog promotes somitic chondrogenesis by altering the cellular response to BMP signaling. Genes \& development. 1999; 13: 225-237.

53. Chiang C, Litingtung Y, Lee E, Young KE, Corden JL, Westphal H, Beachy PA. Cyclopia and defective axial patterning in mice lacking Sonic hedgehog gene function. 1996.

54. Wallin J, Wilting J, Koseki H, Fritsch R, Christ B, Balling $\mathrm{R}$. The role of Pax-1 in axial skeleton development. Development (Cambridge, England). 1994; 120: 11091121. 